\title{
AS SECAS NO JEQUITINHONHA: DEMANDAS, TÉCNICAS E CUSTOS DO ABASTECIMENTO NO SEMIÁRIDO DE MINAS GERAIS
}

\author{
Jeter Liano Silva* \\ Eduardo Magalhães Ribeiro** \\ Vico Mendes Pereira Lima ${ }^{* * *}$ \\ Leo Heller**** \\ * Prefeitura Municipal de Montes Claros, Montes Claros, MG, Brasil. \\ * Instituto de Ciências Agrárias da Universidade Federal de Minas Gerais, Montes Claros, MG, Brasil. \\ * Instituto Federal do Norte de Minas Gerais, Montes Claros, MG, Brasil. \\ * Instituto René Rachou da Fiocruz, Belo Horizonte, MG, Brasil.
}

\begin{abstract}
Resumo
Este artigo analisa as secas no Semiárido do vale do Jequitinhonha, em Minas Gerais, investigando a demanda por água, as técnicas utilizadas, as organizações públicas dedicadas ao abastecimento e seus custos. Para isso, foram utilizadas entrevistas com agências públicas e agricultores de quatro municípios. Conclui-se no artigo que a seca aguda de 2012 a 2016 engajou várias agências públicas no provimento de água, como emprego de técnicas de custos e eficácia diferentes; observou-se que várias inovações técnicas e institucionais ajudam a reduzir o clientelismo que vigora historicamente nas secas; mesmo assim, as maiores despesas continuam a ser com o atendimento emergencial mediado pelo poder local.

Palavras-chave

Secas; Agricultura familiar; Jequitinhonha; Semiárido; Programas públicos.
\end{abstract}




\title{
DROUGHTS IN JEQUITINHONHA: DEMANDS, TECHNIQUES AND COSTS OF SUPPLY IN THE SEMI-ARID REGION OF MINAS GERAIS STATE
}

\author{
Jeter Liano Silva* \\ Eduardo Magalhães Ribeiro** \\ Vico Mendes Pereira Lima*** \\ Leo Heller ${ }^{* * * *}$ \\ * Prefeitura Municipal de Montes Claros, Montes Claros, MG, Brazil. \\ * Instituto de Ciências Agrárias da Universidade Federal de Minas Gerais, Montes Claros, MG, Brazil. \\ * Instituto Federal do Norte de Minas Gerais, Montes Claros, MG, Brazil. \\ * Instituto René Rachou da Fiocruz, Belo Horizonte, MG, Brazil.
}

\begin{abstract}
This article analyzes droughts in the semi-arid region of the Jequitinhonha valley in Minas Gerais State, investigating the demand for water, the techniques used, public organizations dedicated to supply and their costs. Interviews with public agencies and farmers from four municipalities were used. The article concludes that the acute drought of 2012 to 2016 engaged several public agencies in the provision of water, which employed techniques of different costs and effectiveness; it notes that some technical and institutional innovations contribute to reducing clientelism that has historically prevailed in the droughts; even so, the biggest expenses are, still, with the emergency service, mediated by the local power.
\end{abstract}

Keywords

Drought; Family farming; Jequitinhonha; Semi-Arid; Public programs. 


\title{
AS SECAS NO JEQUITINHONHA: DEMANDAS, TÉCNICAS E CUSTOS DO ABASTECIMENTO NO SEMIÁRIDO DE MINAS GERAIS'
}

\author{
Jeter Liano Silva \\ Eduardo Magalhães Ribeiro \\ Vico Mendes Pereira Lima \\ Leo Heller
}

1. Introdução

O Semiárido brasileiro é uma vasta região com quase 1 milhão de quilômetros quadrados. O clima é quente e seco, com índices de precipitação situados entre $400 \mathrm{~mm}$ e $800 \mathrm{~mm}$ anuais concentrados em curtos períodos. Nessa região, secas periódicas costumam estrangular a oferta de água, reduzir a produção agrícola e provocar escassez de alimentos.

As secas agudas no Semiárido do médio e baixo rio Jequitinhonha - a nordeste do estado de Minas Gerais - estimularam organizações estatais e da sociedade civil a criar programas que usam técnicas para perenizar o abastecimento ou atender urgências. Essas técnicas, combinadas à mobilização da população rural, ao escopo das organizações e aos recursos disponíveis, são decisivas para assegurar água. Entender como agricultores, organizações, técnicas e despesas conformam a lida com a seca é importante para orientar ações, reduzir custos e dar segurança ao abastecimento; além disso, permite avaliar técnicas, planejar investimentos e prevenir os abusos que, fatalmente, vicejam com o clientelismo que grassa com as secas.

1. A pesquisa que deu origem a este artigo foi apoiada pelos Territórios da Cidadania do Médio e Baixo Jequitinhonha e contou com recursos do CNPq e da Fapemig, aos quais os autores agradecem. 
Este artigo analisa a dinâmica das secas no rural do Semiárido do Jequitinhonha mineiro: a demanda por água por parte da população rural, as técnicas usadas pelas organizações para atendê-las, a avaliação que agricultores fazem das técnicas e os custos do abastecimento. Além disso, procura compreender a distribuição dos custos entre organizações públicas - governos federal e estadual, prefeituras municipais, ONGs e organizações religiosas.

\section{Semiárido e secas}

As características do clima semiárido - chuva escassa com distribuição irregular no tempo e no espaço, além de períodos de estiagens severas - justificam sua associação com seca e pobreza. Essa relação foi estabelecida desde o começo do século XX pelo clássico Os Sertões, de Euclides da Cunha (1995), publicado em $1902 \mathrm{e}$ que ocupou o imaginário brasileiro. A crítica à generalização da relação entre seca e pobreza apareceu num estudo também clássico sobre o rural brasileiro: Gilberto Freyre (1961) escreveu que aos "sertões" sempre se associava a seca e, à seca, "obras contra a seca”. No senso comum dos brasileiros, secas explicariam "pobreza” e "atraso"; exigiriam, portanto, açudes e frentes emergenciais de trabalho. Essa noção, explicou Freyre, simplificava excessivamente a compreensão dessa porção do Brasil porque limitava uma região à sua ecologia; população, cultura e identidade ficariam subordinadas aos caprichos do clima, à premência das obras e à caridade dos estados ricos do sul do país.

A crítica à interpretação simplista das secas foi assunto para muitos autores, que notaram pelo menos dois equívocos importantes nesse discurso nacional e hegemônico. Primeiro, que essa interpretação construía um recorte espacial ao mesmo tempo geográfico e discriminador - ou que era geográfico exatamente para discriminar -, e o Semiárido seria delimitado para ser estigmatizado, desqualificado e, por fim, subordinado (OLIVEIRA, 1977; ALBUQUERQUE JÚNIOR, 2001). Segundo, que esse discurso tinha o propósito de elidir as especificidades socioeconômicas do Semiárido: a estrutura fundiária concentrada, a distribuição desigual de renda, a ânsia das elites para buscar o benefício privado nas "obras contra as secas" e, por fim, a grande diversidade climática, natural e cultural que tornava impossível considerar a região homogênea (ANDRADE, 1964; FACÓ, 1976; MARTINS, 1981; GOMES, 2001; SILVA, 2007; MALVEZZI, 2007; ASSIS, 2012). Assim, para compreender o Semiárido brasileiro, seria preciso ir além do clima e perceber que, nesse encontro entre ecologia e sociedade, existe uma história de subordinação e tutela, e que secas, afinal, são fenômenos naturais que se manifestam em uma sociedade em que é desigual a distribuição de água, mas também a de terra, de poder e de direitos. 
Apesar dessas ponderações, o "combate à seca" continuou proporcionando ganho político, fortalecendo o mandonismo e o latifúndio e perpetuando oligarquias políticas. Não em consequência do clima, mas em função das relações instituídas pelo poder local e pela apropriação de programas públicos. Assim, as técnicas usadas para "enfrentar as secas" expressaram interesses em vantagens que eram evidentes, embora nunca explicitadas (ANDRADE, 1964; SILVA, 2007).

A crítica aos ganhos políticos e privados com a seca, ao abandono de muitas das "obras contra a seca” assim que chegavam as chuvas, bem como à falta de resultados duradouros no "combate à seca”, fez surgir a proposta de convivência com o Semiárido (SILVA, 2007; MALVEZZI, 2007; ASSIS, 2012). Dessa perspectiva, esboçada originalmente na obra de José Guimarães Duque (2004), era preciso considerar como dadas as especificidades do clima semiárido. As características ecológicas eram definidas, a seca um fenômeno recorrente, e era inútil, além de dispendioso, o esforço para combater o clima com o propósito de copiar estilos de vida e produção de áreas chuvosas. Antes, seria necessário adotar sistemas produtivos adaptados ao clima e pouco exigentes em irrigação, formas criativas de captar água, valorizar o conhecimento local sobre recursos naturais e transformar as condições ecológicas em vantagens e diferenciais. Essa proposta se expandiu nas últimas décadas do século XX e reuniu agricultores, ONGs e setores de agências públicas para criar programas participativos e descentralizados (MALVEZZI, 2007; ASSIS, 2012; GOMES, 2012).

Ações de "combate" e esforços por "convivência” com o clima são perspectivas diferentes. Embora, às vezes, possam ficar turvas as diferenças entre uma e outra abordagem, elas diferem no fundamental, ao propor relações diversas com participação social, exploração do estigma da seca, autonomia, clientelismo e volume de investimentos. Afinal, expressam dois propósitos: perpetuar o mandonismo político com ações caras e descontínuas de "combate à seca" ou, então, descentralizar ações e incorporar saberes locais para "conviver” com as características naturais do clima.

Como em todo o Semiárido brasileiro, essas divergências também se manifestam em Minas Gerais. Nesse estado, o Semiárido inclui parte do vale do rio Jequitinhonha, abarcando Caatinga, Cerrado, Mata Atlântica e a transição entre esses biomas; no sentido leste-oeste vai da divisa de Minas Gerais com a Bahia até a foz do rio Araçuaí. Essa área, de grande diversidade ambiental, cultural e demográfica, corresponde exatamente aos Territórios da Cidadania do Médio e Baixo Jequitinhonha na divisão territorial criada em 2005 pelo extinto Ministério do Desenvolvimento Agrário (MDA). Na demarcação estabelecida pelo governo de 
Minas Gerais em 2015, correspondia aproximadamente ao Território do Médio-Baixo Jequitinhonha (MIN, 2006; MDA, 2010; FJP, 2018).

O povoamento colonizador do Médio e Baixo Jequitinhonha começou no século XIX, quando grupos de agricultores emigrados do Distrito Diamantino buscavam terras "novas" de matas, índios e minério. Em finais daquele século chegaram levas de migrantes do sudoeste da Bahia que implantaram uma pecuária de corte das mais produtivas do Brasil até meados do século XX. Ao longo da história, migrações, a abertura de fronteiras agrícolas e a pecuária resultaram em uma sociedade agrária marcada pelo complexo latifúndio-minifúndio - pequenas posses de agricultores familiares e grandes fazendas de criação -, que, no século XXI, ainda caracteriza esses Territórios. A fazenda fundamentou seu mando na apropriação dos recursos naturais e no controle do poder municipal. A agricultura familiar sempre foi maioria nos estabelecimentos rurais, mas, com fração reduzida da área agrícola, ocupou terras menos férteis, mais exploradas e distantes das águas (FJP, 2018).

Por conta dessa distribuição desigual de recursos naturais, renda e poder, pela base primária da economia regional e pelos indicadores sociais, de acordo com a FJP (2018), desde os anos 1970 o vale do Jequitinhonha é associado pelo senso comum e pelos programas públicos à migração, ao atraso e à seca. Foi o estigma do "vale da pobreza" que levou os governos militares e os que se seguiram a implantar programas de desenvolvimento rural baseados no consumo intenso de recursos naturais: florestas de eucaliptos, barragens, estímulos à mineração e ao crédito rural, que ao longo do tempo acentuaram desigualdades. A adversidade, contraditoriamente, fortaleceu a organização das comunidades rurais; os "lavradores”, que se definem desde os anos 1990 como agricultores familiares, criaram sindicatos, conselhos e movimentos, fortaleceram agências de assessoria que valorizaram o conhecimento local, a luta por terra e programas de desenvolvimento rural (GALIZONI, 2007; CALIXTO et al., 2009; FJP, 2018).

Estudo realizado por Galizoni e colaboradores (2013) mostra que esses lavradores não incorporaram à produção as técnicas da revolução verde. $\mathrm{O}$ que eles fazem é a lavoura tradicional de "mantimentos" - alimentos da lavoura anual -, coleta, beneficiamento primário e comercialização da produção em circuitos curtos, em trocas comunitárias e feiras livres urbanas. As comunidades rurais criaram regras costumeiras de uso e manejo à medida que minguaram os recursos naturais e cresceu a população. Por costume, valorizam as “águas pequenas” das nascentes, estabelecem partilhas nos períodos de escassez, retaliam a concentração, o represamento e o consumo elevado de água. Para fazer isso, classificam, hierarquizam, conservam e normatizam as fontes de águas. E, à medida que a água escasseia, 
operam com escalas de prioridade: privilegiam água de nascente para beber, selecionam os animais que serão vendidos, abandonam temporariamente, e de acordo com critérios predefinidos, as atividades que mais consomem água. As estratégias para conviver com o período de seca exigem essa racionalização; não se restringem a captar e acumular água: antes, são técnicas culturais de gestão das fontes, do consumo e da escassez que expressam arranjos costumeiros.

\section{Procedimentos metodológicos}

A pesquisa que originou este artigo se iniciou em 2016 com entendimentos com os Colegiados dos Territórios da Cidadania do Médio e Baixo Jequitinhonha. Os Territórios da Cidadania eram fóruns criados pelo Governo Federal, por meio do extinto MDA, para descentralizar programas de desenvolvimento (BRASIL, 2005; DELGADO, GRISA, 2014). Com esses colegiados foi combinado o escopo da pesquisa, e a eles foram solicitados apoio nas atividades de campo e sugestão dos locais que seriam pesquisados. Como a seca incide de maneira diferente em lugares diferentes, foi preciso estudar municípios maiores e menores em população e rendas - estas são derivadas de repasses federais e proporcionais ao tamanho da população -, incluídos no Semiárido legal e que passavam por secas severas. As plenárias dos Colegiados dos Territórios indicaram para o Baixo Jequitinhonha os municípios de Jequitinhonha, mais populoso, e Rubim; Araçuaí, de maior população, e Cachoeira de Pajeú, de população menor, foram os indicados para o Médio Jequitinhonha.

Em seguida, e também por indicação dos Colegiados dos Territórios, foram entrevistados agentes de instituições públicas que lidam com secas: secretários municipais responsáveis pelo abastecimento emergencial de água, técnicos da Empresa de Assistência Técnica e Extensão Rural (Emater/MG), Sindicatos dos Trabalhadores Rurais (STRs) e Conselhos Municipais de Desenvolvimento Rural Sustentável e Solidário (CMDRSSs) dos quatro municípios. Além disso, foram entrevistados técnicos das Cáritas Diocesanas de Almenara e de Araçuaí (gestoras do Programa Um Milhão de Cisternas Rurais, P1MC, da Articulação do Semiárido, ASA, além de outras iniciativas), equipes do Instituto de Desenvolvimento do Norte e Nordeste de Minas Gerais (Idene), da ONG Centro Popular de Cultura e Desenvolvimento (CPCD) e a coordenação da Defesa Civil. Foram feitas entrevistas semiestruturadas em busca de informações tanto quantitativas como qualitativas sobre história, metodologia de ação da instituição, programas, técnicas e custos do abastecimento de água. Essas agências forneceram dados e documentos e indicaram novas fontes de informações - inclusive motoristas de caminhão-pipa, pedreiros, gestores de águas e lideranças em comunidades rurais -, criando uma 
cadeia de contatos que permitiu compreender os conflitos, as rotinas e as soluções locais relacionados às secas ${ }^{2}$.

Foi o conhecimento dos técnicos dessas instituições sobre as secas nos municípios indicados que orientou a escolha das comunidades rurais pesquisadas. Os técnicos entrevistados eram "especialistas”, conforme Brandão (1986) e Posey (2001): detinham grande saber a respeito da seca e das suas consequências. Assim, indicaram comunidades rurais que atravessavam situações recorrentes de escassez, que experimentaram o cardápio de técnicas usadas para abastecimento emergenciais, duradouras, de alto e baixo custo - e que, portanto, tinham avaliação amadurecida sobre a qualidade de programas e técnicas. Na verdade, em um mesmo município, as situações críticas de abastecimento eram igualmente conhecidas por todos; eram consensos firmados entre instituições de natureza e, às vezes, até de perspectivas diferentes, como Sindicato e Secretaria de Agricultura. Técnicos de agências distintas faziam narrativas idênticas sobre as secas, indicavam as mesmas áreas críticas, conheciam a situação delas, assim como o histórico das alternativas experimentadas. Muitas vezes, ofereceram-se para mediar o contato com lideranças de comunidades rurais.

Com base nessas indicações, foram escolhidas oito comunidades rurais que atravessavam situação crítica e eram, ao mesmo tempo, emblemáticas da experimentação de técnicas e ações empregadas para promover o abastecimento. Foram indicadas Tesouras de Cima e São José das Neves, em Araçuaí; Fazenda 21 e São Domingos, em Cachoeira de Pajeú; Chapadinha e Assentamento Franco Duarte, em Jequitinhonha; Empedrado e Assentamento Jerusalém, em Rubim. Em cada comunidade rural, três famílias indicadas pelos dirigentes dos Sindicatos de Trabalhadores Rurais foram entrevistadas e responderam a perguntas sobre produção agrícola, água, estratégias de gestão do recurso, atendimento das demandas e mediações envolvidas no abastecimento.

Às entrevistas foram reunidos documentos fornecidos pelas instituições, as impressões vindas da observação do meio físico, as peculiaridades culturais e os preceitos das famílias rurais e das agências que lidam com a seca. Assim, foi possível compreender a efetividade de determinadas ações e o desperdício inerente a outras, fundamentar uma apreciação dos programas e técnicas, comparar os gastos

\footnotetext{
2. Sobre essas técnicas de pesquisa, consultar Laville e Dionne (1999), Gil (2010), Minayo et al. (2009) e Amorozo et al. (2002). LAVILLE, C.; DIONNE, J. A construção do saber. Belo Horizonte: Editora UFMG, 1999. GIL, A. C. Como elaborar projetos de pesquisa. 5. ed. São Paulo: Atlas, 2010. MINAYO, M. C. S. et al. Pesquisa social: teoria, método e criatividade. 28. ed. Petrópolis: Vozes, 2009. AMOROZO, M. C. M.; MING, L. C.; SILVA, S. M. P. Métodos de coleta e análise de dados em etnobiologia, etnoecologia e disciplinas correlatas. Rio Claro: Unesp/SBEE, 2002.
} 
com técnicas e perceber, pela solidez e replicação dos dados, que algumas delas são superiores em resultados. Esse conjunto permitiu entender, inclusive, por que são conservadas técnicas de alto custo e com resultados modestos.

O cálculo dos custos do abastecimento seguiu o padrão definido nos contratos. Existe um conjunto restrito de técnicas e ações, quase todas disseminadas nos dois Territórios. Para cada uma delas há um orçamento padronizado, definido pelo contratante (por exemplo, para as cisternas de placa e poços artesianos), ou custos determinados pelos prestadores de serviços (por exemplo, para as horas-máquinas necessárias para fazer uma barraginha), ou, ainda, preços estabelecidos para serviços contínuos (por exemplo, o caminhão-pipa). Por outro lado, o número total de técnicas (cisternas construídas em um município, por exemplo) e a quantidade de ações repetidas para determinado período (viagens de caminhão-pipa em um mês) também são registrados pelas organizações que lidam com as secas. Portanto, para chegar aos custos anuais, foi necessário (i) identificar todas as técnicas e ações praticadas no município e, em seguida, (ii) orçá-las, (iii) levantar seu número total, (iv) apurar o total da despesa por técnica ou ação e, por fim, (v) determinar a vida útil de cada uma delas, para, então, (vi) definir custos por ano. Todos esses valores foram fornecidos por organizações que atuavam com secas tomando como referência o ano de 2016.

Ressalve-se que o gasto do município de Araçuaí foi usado como base de cálculo dos custos com caminhão-pipa de todos os municípios, por serem registros sistemáticos e de longo prazo. Esse custo incluía os itens aluguel de caminhão terceirizado, manutenção, combustível e motorista. A base para o cálculo do cercamento de nascentes foi o investimento nessa ação realizado no município de Jequitinhonha. Os custos com cisternas de placa de 16 mil litros e 52 mil litros seguiram a planilha da ASA/Brasil - Cáritas, auditada pelo Tribunal de Contas da União. Os custos para a construção de tanques, poços e barragens foram estimados com base no número médio de horas demandadas em cada obra e no preço médio de hora-máquina nos Territórios. Finalmente, os custos com perfuração de poços artesianos seguiram a tabela de preço médio informada pelo Idene/MG. A vida útil dos equipamentos e técnicas foi igualmente estimada pelas organizações gestoras.

\section{As secas do Jequitinhonha}

\subsection{Agricultores e demandas por água}

As famílias rurais pesquisadas nos Territórios da Cidadania do Médio e Baixo Jequitinhonha eram compostas em média de quatro pessoas que viviam em assentamentos ou na terra em que nasceram, recebida em herança. Nesta, os "terrenos" eram em geral "embolados" - misturados entre os membros da mesma parentela 
- e raramente alcançavam um módulo rural, que, nesses municípios, ficava entre 60 e 65 hectares (Incra, 2018). Cultivavam sobretudo mantimentos, pomares e hortas nas terras frescas de culturas dos "boqueirões"; costumavam plantar também cana-de-açúcar para fazer rapadura e, em Araçuaí, produziam tabaco. Ainda, processavam farinha de mandioca - o Jequitinhonha, principalmente no curso médio, é o maior produtor de Minas Gerais -, criavam pequenos animais no "terreiro" das casas e, nas "mangas de pasto", mantinham cavalos para serviço e vacas que produziam leite para consumo próprio e para a produção de requeijão e queijo.

A renda dessas famílias vinha da lavoura, do beneficiamento da produção, das vendas nas feiras livres, de negócios na localidade - "tramas" e "rolos" - e de prestações de serviços dentro da comunidade. Grande importância era dada aos programas públicos de transferência de renda, notadamente aposentadorias e pensões, além de Bolsa Família e Garantia Safra. O programa público, em períodos críticos, às vezes era a única fonte de renda em dinheiro e podia ser usado para apoiar a produção, por meio da compra de insumos ou da contratação de pequenos serviços, ou para melhorar o abastecimento de água, com a aquisição de mangueiras e caixas-d'água e o custeio de aberturas de cacimbas ou construção de cisternas.

Esses agricultores - secundados por técnicos de órgãos públicos, ONGs, agências religiosas e dirigentes sindicais dos Territórios do Médio e Baixo Jequitinhonha - afirmaram que as chuvas haviam diminuído muito. O Instituto Nacional de Meteorologia (Inmet) confirmou: a média histórica de precipitação nesses municípios entre 1961 e 1990 foi de 823 mm; entre 2012 e 2016, caiu para 574 mm (INMET, 2017). A distribuição dessa chuva foi, também, irregular. E, como no Semiárido há grande perda de água por evapotranspiração, houve queda de volume das nascentes e rios que, além de prejudicados pela estiagem, foram assoreados pela concentração de chuvas em curtos períodos.

Na falta das águas "pequenas" de que gostam, as famílias rurais buscavam aquelas que consideravam ainda ter qualidade e se deslocavam por grandes distâncias para consegui-las em nascente que ainda não secara, partilhada por parentes ou conhecidos. Mas, com o tempo, tiveram que relaxar o preceito cultural que prioriza o consumo doméstico de águas "pequenas” e correntes; para suportar a escassez, tiveram de usar, cada vez com mais frequência, águas "presas” em poços, reservatórios e cisternas. Sempre, em todos os casos pesquisados, e também nos relatos de técnicos, famílias rurais combinavam diferentes fontes de águas, de qualidades variadas. Afinal, como dizem, "qualquer roupa veste o nu". Apesar da escassez e da distribuição incerta das chuvas, enquanto foi possível, conservaram animais e lavouras de mantimentos, mesmo "passando apertados" para partilhar com as criações a pouca água dos reservatórios e arcando com perdas na lavoura 
- inclusive de plantas resistentes à estiagem, como feijão-andu, feijão-catador e mandioca ${ }^{3}$.

Porém, na seca prolongada tiveram que fazer concessões. Diminuíram as lavouras, reduziram o número de criações e compartilharam a água do uso doméstico com os animais de "terreiro" para poder conservá-los. Acostumaram-se também a reaproveitar a água do banho, de lavagem de vasilhas e de roupas para molhar plantas do quintal ou abastecer os animais. E alteraram hábitos: a higiene pessoal foi reduzida ao mínimo, desfizeram-se de animais, sacrificaram hortas e pomares. No entanto - ao contrário dos relatos frequentes sobre secas do Semiárido -, não houve sequer uma menção, por agricultor ou técnico, à possibilidade de abandonar o lugar em decorrência da seca. Ao contrário: as famílias rurais asseguraram que era possível viver com pouca água e criar estratégias para sobreviver ao período crítico ${ }^{4}$.

No auge das secas, córregos e nascentes perderam vigor e secaram. Foi só quando faltou a fonte de água para a família e a comunidade é que se recorreu aos programas públicos. Na urgência, pouco importava tratar-se de programa de "combate" ou de "convivência" com a seca: esses agricultores avaliam que sempre receberão, por um ou outro método, água de pior qualidade, "grossa”, "pesada” e, principalmente, mediada por relações estranhas ao código costumeiro.

Isso trazia, naturalmente, um conjunto de dificuldades. A reclamação mais comum feita pelos agricultores dos quatro municípios foi a falta de água de qualidade para beber e preparar alimentos. A água para esses fins provinha das caixas de coleta de chuva - cisternas de placas de cimento, com capacidade para 16 mil litros, amplamente difundidas nos Territórios pela ASA/Brasil - Cáritas, previstas para cinco pessoas beberem e cozinharem por seis meses. Com a agudização da seca, o suprimento da cisterna se tornava insuficiente e requeria o aporte da água de baixa qualidade dos caminhões-pipa. Outra dificuldade era a lavoura: perdida esta, eles eram obrigados a comprar o mantimento na cidade. Então, diziam que perdiam no dinheiro e na qualidade do alimento "trazido de fora"; consideravam, além disso, que perdiam na segurança e na soberania alimentar, bem como no trabalho desperdiçado nas lavouras ou ocioso pela falta destas. E a perda da lavou-

\footnotetext{
3. Sobre a combinação de diferentes fontes de água no Semiárido mineiro, ver Araújo et al. (2010); sobre a contenção e a hierarquização de consumo, ver Galizoni et al. (2013). ARAÚJO, V. M. et al. Águas no rural do Semiárido mineiro: uma análise das iniciativas para regularizar o abastecimento em Januária. Lavras: Organizações Rurais \& Agroindustriais, v. 12, n. 2, 2010.

4. Para uma análise da relação entre seca e migrações, consultar Durhan (1973); esse trabalho indica que as relações sociais, muito mais que as secas, influem na mobilidade de populações rurais. DURHAN, E. R. A caminho da cidade: a vida rural e a migração para São Paulo. São Paulo: Perspectiva, 1973.
} 
ra repercutia nas áreas urbanas, abastecidas com regularidade e qualidade pelas feiras livres da agricultura familiar.

Com a seca, os lavradores eram obrigados a apresentar suas demandas por água para agências públicas, ou recorrer ao clientelismo, fazendo pedidos de água a vereadores, mediadores e chefes políticos. Assim, as demandas e os custos das secas combinavam urgências e negociações com um elenco restrito de técnicas e ações que abasteciam as famílias rurais. Essas demandas fluíam por diversos canais - alguns deles formalizados: CMDRSSs, STRs e associações comunitárias, que são espaços de expressão direta ou de representação dos agricultores. Esses canais tinham capilaridade, seus agentes conheciam a situação das comunidades e famílias e verbalizavam as demandas coletivas por atendimento de urgência ou por ações duradouras de abastecimento de água. Já outros canais eram menos formalizados ou, até, absolutamente informais: o pedido ao funcionário de órgão público ou ao político, principalmente ao vereador.

\subsection{Agências públicas e suas ofertas}

O cardápio de técnicas de abastecimento disponíveis para determinado local é, de certo modo, restrito. Depende de capacidades institucionais, características próprias do ambiente, saber local, redes de cooperação e experiência no uso de técnicas. A combinação dessas variáveis delimita, em cada território do Semiárido, as técnicas que permitem aos agricultores "combater" ou "conviver" com a seca.

Em 2016, nos Territórios da Cidadania do Médio e Baixo Jequitinhonha, foram encontrados seis tipos de agências públicas especializadas em lidar com água e seca: i) as Secretarias Municipais de Desenvolvimento, Ambiente ou Agricultura, responsáveis pelo abastecimento regular ou emergencial de água; ii) as Cáritas das dioceses católicas de Almenara e Araçuaí, executoras dos programas da ASA/ Brasil; iii) o Idene, executor de programas do Governo do Estado de Minas Gerais; iv) a Emater/MG, executora de programas sociais e de desenvolvimento rural; v) os CMDRSSs, instâncias municipais com participação paritária da sociedade civil e agências estatais; vi) os STRs, órgãos de representação de agricultores familiares. Além dessas, a ONG CPCD desenvolvia ação restrita a Araçuaí no Projeto Arasempre.

Com exceção da última, essas instituições atuavam em todos os municípios dos dois Territórios captando demandas, gerindo ações de abastecimento, negociando projetos e adequando programas que, muitas vezes, "chegavam prontos" das capitais do estado e da federação. Em 2016, eram oito as ações e/ou técnicas usadas, descritas a seguir. 
1. Cisterna de placa de 16 mil litros: técnica e ação da ASA/Brasil - Cáritas e da CPCD em Araçuaí, de disseminação generalizada; consiste em uma caixa de cimento que capta água de chuva nos telhados. Era bem avaliada por agricultores e gestores porque reduzia a penosidade da captação, por fornecer autonomia, por admitir complementar o abastecimento e por possibilitar a continuidade do Programa, conduzido por uma década e meia, mesmo nos anos de chuvas regulares;

2. Cisterna de placa de 52 mil litros: técnica e ação da Cáritas - ASA/Brasil, componente do Programa Uma Terra e Duas Águas, P1+2; a caixa é acoplada a telheiros, terreiros ou enxurradas para abastecer hortas e animais; muito bem avaliada por agricultores e agentes de desenvolvimento, porém com atendimento a número reduzido de famílias;

3. Poço artesiano: ação e técnica do Idene e das prefeituras para captar águas subterrâneas. Era bem avaliado quando funcionava; mas técnicos e agricultores afirmavam que eram poucos poços, de água salobra ou ferruginosa, às vezes com restrição de acesso por serem perfurados em áreas particulares, ou abertos às margens de córregos, contrariando normas ambientais. Era criticado também porque, além do alto custo, segundo o próprio Idene no Jequitinhonha, apenas $10 \%$ dos poços perfurados forneciam água;

4. Barramentos e escavações: ações disseminadas por prefeituras, são represas e "poços baianos" (ou "poço amazonas", de acordo com a classificação de Vasconcelos (2014)), que retêm águas de córregos ou enxurradas. Eram bem avaliados para o abastecimento de animais e plantações; no entanto, secavam no decorrer do ano, os agricultores precisavam pagar parte dos gastos da obra e havia pequeno número de máquinas disponíveis para construí-los;

5. Cercamento de nascentes: ação de prefeituras e da Emater com o objetivo de conservar fontes de água. Era bem avaliado, embora agricultores não o identificassem como ação de abastecimento, em razão de não permitir acesso imediato à água;

6. Barraginhas: ação de prefeituras e do CPPD, são cavas com função de infiltrar água de chuva no lençol freático. Bem avaliadas, não eram, porém, vistas pelos agricultores como ação de abastecimento, a despeito de con-

5. Sobre penosidade para captar água no Semiárido, ver Aleixo et al. (2016); sobre as cisternas do P1MC, ver Malvezzi (2007) e Assis (2012); para uma avaliação, ver Gomes (2012). ALEIXO, B. et al. Direito humano em perspectiva: desigualdades no acesso à água em uma comunidade rural do Nordeste brasileiro. Ambiente \& Sociedade. São Paulo v. XIX, n. 1, jan.-mar. 2016. 
sideradas importante por manter a umidade no solo, permitir plantios e recuperar nascentes;

7. Caminhão-pipa: ação generalizada das prefeituras, vista pelos agricultores como a principal solução para emergências. Entretanto, raramente oferecia água de qualidade, o atendimento demorava, era instrumentalizado por interesses políticos e tinha custo elevado. Ainda, gestores municipais avaliavam que a capacidade dinâmica de estocagem da cisterna de placa multiplicava exageradamente a demanda pelo caminhão-pipa;

8. Programas de crédito e transferência de renda: ações disseminadas do Governo Federal, conduzidas pelas prefeituras e pela Emater, propiciavam recursos que os agricultores investiam em canalização e técnicas de captação de água, principalmente cacimbas, poços e novas cisternas de placa.

Essas técnicas e ações, tanto emergenciais quanto de longo prazo, contínuas ou assistemáticas, atendiam às populações rurais por meio de diferentes sistemas de gestão. Algumas eram participativas, outras eram centralizadas; algumas estimulavam autonomia, outras sedimentavam dependência. Mas, na urgência, com qualquer origem ou método, técnicas e ações eram bem acolhidas por famílias que careciam de água.

\subsection{Custos da seca}

Ações e técnicas têm custos variados, dimensionados neste estudo por programa, município, instituição executora e cidadão(ã) e, por fim, comparados com outras despesas públicas.

A Tabela 1 apresenta os custos por técnica ou ação, computando todas as despesas executadas nos municípios entre 2002 e 2016. É necessário informar que, seguramente, os custos estão subestimados: primeiro, porque não incluem despesas feitas com recursos da própria família rural; segundo, porque não computam recursos desperdiçados, como poços artesianos que não produzem água; terceiro, por não incorporarem ações localizadas e dispersas nas comunidades realizadas por organizações religiosas e solidárias. Nessa tabela sobressai a magnitude dos investimentos regulares em cisternas de placa, embora os trinta anos de vida útil desses equipamentos diluam essas despesas, que alcançam apenas $13,24 \%$ dos gastos anuais com as secas. Cabe ressaltar, ainda, o gasto diminuto na conservação de recursos hídricos: cercamentos de nascentes (0,38\%) e barraginhas (0,05\%). Essas técnicas, reputadas pelos bons efeitos no longo prazo, somam apenas 0,43\% do dispêndio médio total por ano. Poços artesianos, que combinam custo alto e baixa efetividade, representam fração modesta da despesa (2,62\%). Na tabela, destaca-se 
também o gasto emergencial com o caminhão-pipa, que representa 82,65\% da despesa anual com secas nos quatro municípios. Barragens, tanques e poços baianos, técnicas simultaneamente duradouras e de efeito no curto prazo, absorveram apenas $1,06 \%$ do gasto.

\begin{tabular}{l|c|c|c|c|c}
\hline Técnica & $\begin{array}{c}\text { Investimento } \\
(\mathrm{R} \$)\end{array}$ & Número & $\begin{array}{c}\text { Vida útil } \\
(\text { ano })\end{array}$ & $\begin{array}{c}\text { Despesa/ ano } \\
(\mathrm{R} \$)\end{array}$ & $\begin{array}{c}\text { Percentual } \\
(\%)\end{array}$ \\
\hline Cisterna de placa 16 mil L & $8.634 .500,00$ & 2.467 & 30 & $287.816,67$ & 7,87 \\
\hline Cisterna de placa 52 mil L & $5.892 .000,00$ & 492 & 30 & $196.400,00$ & 5,37 \\
\hline Cercamento de nascentes & $345.000,00$ & 115 & 25 & $13.800,00$ & 0,38 \\
\hline Barragens e tanques & $1.283 .000,00$ & 102 & 40 & $32.075,00$ & 0,87 \\
\hline Barraginhas & $7.500,00$ & 20 & 4 & $1.875,00$ & 0,05 \\
\hline Poços baianos & $70.000,00$ & 500 & 10 & $7.000,00$ & 0,19 \\
\hline Poço artesiano & $2.400 .000,00$ & 32 & 25 & $96.000,00$ & 2,62 \\
\hline Caminhão-pipa (locação/ano) & - & 21 & - & $3.024 .000,00$ & 82,65 \\
\hline Total & $18.632 .000,00$ & - & - & $3.658 .966,67$ & 100,00 \\
\hline
\end{tabular}

Tabela 1. Despesas de custeio e investimento por técnica de abastecimento de água em áreas rurais, Médio e Baixo Jequitinhonha, municípios selecionados, 2002-2016.

Fonte: Elaborada pelos autores com base em dados fornecidos pelas instituições responsáveis pelos programas nos municípios. Valores de 2016. A estimativa de vida útil foi feita pelas organizações coordenadoras dos programas.

A Tabela 2 apresenta os gastos com secas por município. Percebe-se que o montante de despesas é diretamente proporcional ao tamanho da população rural, mas é preciso lembrar que as receitas municipais são igualmente proporcionais à população. Assim, municípios mais populosos apresentam maior condição de atendimento e, embora a demanda por água também seja maior, têm melhores condições para negociar, adaptar e diversificar programas. Araçuaí, com o CCPD/ Arasempre, é um bom exemplo, pois faz parcerias, oferece contrapartidas e negocia novas ações. Mesmo assim, há grande disparidade na despesa per capita, que varia de $\mathrm{R}$ \$ 179,74 (Araçuaí) a R \$ 81,98 (Cachoeira de Pajeú), indicando diferenças na prioridade de gastos, na qualidade do atendimento ou nos custos maiores da logística - determinados pelo tamanho do município e pela distribuição espacial da população rural sem fontes naturais de água. A Tabela 2 permite também observar o custo médio anual da seca por pessoa na zona rural desses municípios: $\mathrm{R} \$ 118,95$. Como a renda anual média per capita neles montava a $\mathrm{R} \$ 4.691,28^{6}$, os custos anuais médios com a seca equivaleriam a $2,54 \%$ dessa renda.

6. A renda média foi obtida por meio da média aritmética das rendas per capita dos quatro municípios pesquisados disponíveis no Atlas do Desenvolvimento Humano no Brasil (2017). 


\begin{tabular}{l|c|c|c|c}
\hline Município & $\begin{array}{c}\text { Despesa média } \\
\text { anual (R\$) }\end{array}$ & Número de ações & População rural & $\begin{array}{c}\text { Despesa per } \\
\text { capita (R\$) }\end{array}$ \\
\hline Araçuaí & $2.260 .738,33$ & 2.311 & 12.578 & 179,74 \\
\hline Cachoeira de Pajeú & $368.765,00$ & 766 & 4.498 & 81,98 \\
\hline Jequitinhonha & $808.413,33$ & 298 & 7.070 & 114,34 \\
\hline Rubim & $221.050,00$ & 364 & 2.216 & 99,75 \\
\hline Média & $914.741,67$ & 935 & 6590 & 118,95 \\
\hline
\end{tabular}

Tabela 2. Despesa média anual com a seca, número de ações, população rural e despesa per capita com abastecimento rural em municípios selecionados do Semiárido do vale do Jequitinhonha, 2016.

Fonte: Pesquisa de campo (2016); IBGE/Censo (2010).

As despesas com seca se distribuíam entre instituições públicas em proporções diferentes. A Tabela 3 mostra que a maioria das despesas recaía sobre o Governo de Minas Gerais (44,60\%) e, em seguida, sobre as prefeituras municipais $(40,51 \%)$. Observa-se que a maioria desses dispêndios se destinava a caminhões-pipa: 82,65\%. Grande parte das despesas do Governo Federal (12,90\%) e a totalidade das despesas de Cáritas e das ONGs foram com programas de conservação e convívio com a seca: P1MC e P1+2, de captação e uso descentralizado de águas de chuvas, ações consideradas essenciais pelas famílias rurais no tocante ao abastecimento.

\begin{tabular}{|c|c|c|c|}
\hline Instituição & Ação & Despesa $(R \$)$ & Percentual (\%) \\
\hline \multirow{2}{*}{ Governo de Minas Gerais } & Caminhão-pipa & $1.584 .000,00$ & 43,29 \\
\hline & Poço artesiano & $48.000,00$ & 1,31 \\
\hline \multirow{2}{*}{ Governo Federal } & Poço artesiano & $48.000,00$ & 1,31 \\
\hline & Cisterna de placa & $471.966,67$ & 12,90 \\
\hline \multirow{4}{*}{ Prefeitura Municipal } & Caminhão-pipa & $1.440 .000,00$ & 39,36 \\
\hline & Barragem & $31.325,00$ & 0,86 \\
\hline & Cercamento de nascentes & $3.720,00$ & 0,10 \\
\hline & Poço-baiano & $7.000,00$ & 0,19 \\
\hline \multirow{4}{*}{ ONGs / Cáritas } & Cisterna de placa & $12.250,00$ & 0,33 \\
\hline & Barragem & 750 & 0,02 \\
\hline & Barraginha & $1.875,00$ & 0,05 \\
\hline & Cercamento de nascentes & $10.080,00$ & 0,28 \\
\hline Total & - & $3.658 .966,67$ & 100,00 \\
\hline
\end{tabular}

Tabela 3. Instituições e despesas médias anuais com seca no vale do Jequitinhonha, 2016 Fonte: Pesquisa de campo (2016). 
O Fundo de Participação dos Municípios (FPM) era a principal fonte de receita dos quatro municípios, com valores médios de $\mathrm{R} \$$ 12.760.960,22 em 2016. A despesa com a seca correspondeu a $7,17 \%$ dessa receita. Percebe-se que os custos da seca equivaliam a 59,73\% das despesas com saúde, 9,54\% das despesas com educação e 17,44\% dos pagamentos médios do Programa Bolsa Família nos municípios, conforme se vê no Gráfico 1.

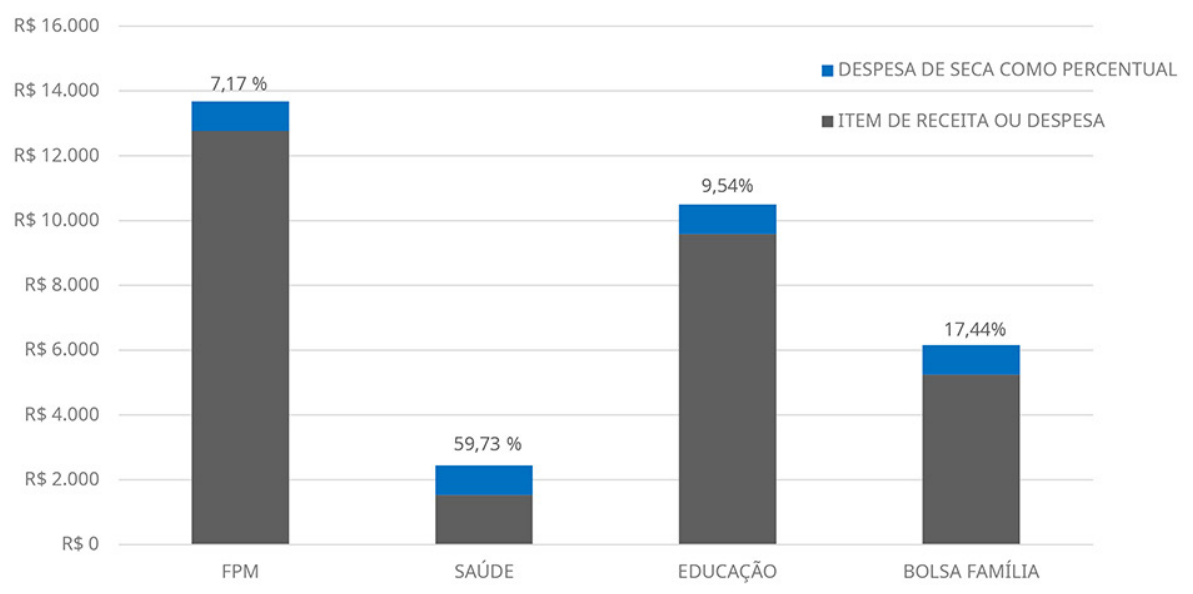

Gráfico 1. Despesas médias com a seca como percentual das principais despesas médias feitas em quatro municípios do Semiárido do vale do Jequitinhonha, em milhares de reais (R\$) e percentuais (\%), 2016.

Fonte: Portal da Transparência (2017); TCEMG (2017).

Por fim, é preciso considerar que o custo para abastecer de água uma pessoa na zona rural do Semiárido do Jequitinhonha é superior ao preço do abastecimento urbano em Minas Gerais. O consumo médio por pessoa/mês em área urbana no estado, de acordo com a Companhia de Saneamento de Minas Gerais (Copasa), era de 3,5 m³ ou 116,66 L pessoa/dia, com tarifa mínima de abastecimento residencial de $\mathrm{R} \$ 2,19$ por $\mathrm{m}^{3}$ ou $\mathrm{R} \$ 91,98$ por pessoa/ano 7 . O custo médio de provimento de água nos anos de seca para habitante de área rural no Semiárido do Jequitinhonha chegava a $\mathrm{R} \$ 118,95$ por pessoa/ano, ou seja, 29,32\% acima da mesma despesa na zona urbana. É preciso considerar, ainda, a subestimação do custo do abastecimento rural, a qualidade certamente inferior da água oferecida ali, além do fato de que o

7. Disponível em: http://mzweb.com.br/copasa/web/arquivos/COPASA_SPCM_17102006_port.pdf. Acesso em: 6 jun. 2017. 
consumo urbano representa mais do que o dobro do consumo observado na seca da área rural do Jequitinhonha ${ }^{8}$.

O Semiárido do vale do Jequitinhonha em Minas Gerais conta com 31 municípios (BRASIL, 2005). Considerando o custo médio observado de uma seca por município em $\mathrm{R} \$$ 914.741,66, podem ser estimados gastos de $\mathrm{R} \$ 28.356 .991,46$ anuais para atender a todos eles. Mas estes são custos monetários. Existem custos não monetários, como o esforço da mulher para coletar, tratar e armazenar água; e existem os custos da dependência pessoal do gestor da água, a troca do recurso pelo apoio ao político e o corte do abastecimento em retaliação ao adversário, os quais recaem sobre famílias rurais que ficam à mercê do mandão ou do "dono" da água. Esses abusos se associam principalmente aos caminhões-pipa e aos poços artesianos, sempre mediados por chefes locais. Coincidentemente, são as técnicas de maior custo.

A instrumentalização desses recursos pelo clientelismo, no entanto, não era automática. Dependia, sobretudo, do canal usado pela família rural para ter acesso à água. Com a utilização de canais informais - o pedido ao deputado, prefeito, vereador ou funcionário -, muitas vezes a concessão da água vinha como favor, sempre com o risco de priorização ou retaliação, enfim, de entrar nas trocas políticas associadas ao controle da distribuição da água. Mas, se o pedido seguia pelo STR ou pelo CMDRSS, a formalização já criava o fato público: exigia análise criteriosa, racionalidade e hierarquização da demanda, que ficava assim mais "cidadã" - menos sujeita a mediações clientelistas. E, como as demandas formais e informais às vezes tendiam para a mesma agência, um gestor de programa de abastecimento poderia simultaneamente atuar de forma "cidadã" e "clientelista”, ao empregar critérios diferentes para atender a um mesmo propósito. No entanto, a formalização e o caráter público das demandas - debates acirrados nos CMDRSSs e STRs sobre escassez, denúncias de desvios e, principalmente, a consolidação de consensos sobre a hierarquia das comunidades rurais com falta de água no município - funcionavam como limites para a ação clientelista. Não eliminavam o clientelismo, mas contribuíam para inibi-lo.

\section{Conclusão}

Nas secas do Médio e Baixo Jequitinhonha, agricultores e organizações públicas se mobilizaram e, com a aplicação de um conjunto de técnicas, asseguraram água para a população rural. As organizações mostraram capacidade para respon-

8. Em Araçuaí, foi possível dimensionar o consumo médio de uma família rural na seca em 50 L/pessoa/ dia; Galizoni et al. (2013) calcularam 47 L/pessoa/dia na estação seca da mesma região. 
der às demandas; entretanto, não conseguiam garantir condições de produção na estação seca e, às vezes, o abastecimento passava pelo clientelismo. Percebe-se que os custos das técnicas de abastecimento são elevados: a despesa com urgências compreende mais de $80 \%$ dos custos da seca; a perenidade e o baixo custo de longo prazo da cisterna de placa contrastam com o custo elevado do serviço emergencial do caminhão-pipa, comprovando a importância da ação constante, planejada e descentralizada.

A introdução da cisterna de placa e de instâncias municipais de decisão sobre a distribuição das águas contribui para minar o clientelismo, revelando que a combinação de novos programas, novas técnicas e novas instituições tem um papel transformador sobre as secas no Semiárido. É por isso que se destacam a importância e a capilaridade das ações da sociedade civil organizada no P1MC, e não apenas por oferecer água: sua importância é principalmente política, por dar autonomia, por assegurar capacidade de reserva para a família rural e por ter dado continuidade ao programa mesmo quando as chuvas voltaram, rompendo o paradigma histórico da curta duração do "combate às secas".

De outro lado, chamam atenção a pequena importância das despesas com iniciativas de conservação de fontes de água e a persistência do atendimento emergencial, mantendo portas abertas para o clientelismo. É relevante destacar o gasto com ações imediatistas e emergenciais, como caminhão-pipa e poço artesiano, técnicas mais caras, de menor efetividade e, no caso do poço, com maior risco de desperdícios porque apenas parte deles produz água. Além disso, estimulam conflitos e são, sob qualquer ponto de vista, insuficientes para atender à população.

Mas as famílias rurais em todos os municípios pesquisados tiveram acesso à água durante a seca prolongada de 2012 a 2016 - ainda que regrada para beber e cozinhar, ainda que mediada às vezes pelo mando político, sempre por meio da cisterna de placa e muitas vezes completada pelo caminhão-pipa. Essas famílias avaliavam a "água da bica" - a água de chuva - como de qualidade, a "melhor água”, quando não dispunham de outras fontes nas secas; porém, sempre precisavam combinar fontes, e por isso todos os programas eram considerados providenciais, mesmo aqueles menos úteis, de maior custo e que faziam exigências em troca da água.

Instituições públicas, principalmente o Estado, deveriam compreender a maneira como as famílias rurais se posicionam diante dos diferentes métodos e técnicas que são oferecidos para conviver com a seca ou para enfrentá-la. Esse posicionamento é a melhor indicação para o gasto de recursos. Além dos programas citados, evidentemente, as famílias rurais criam suas estratégias, como captação de água de nascentes, construção de novas cisternas de placa e de poços baianos, 
captação de água de córregos intermitentes e adaptações nas técnicas propostas pelas instituições, tudo com recursos próprios. E aprendem também a instrumentalizar as instituições, jogando seu jogo de trocas; às vezes, quase sempre, com bom proveito.

\section{Referências}

ALBURQUERQUE JÚNIOR, D. M. A invenção do Nordeste e outras artes. 2. ed. São Paulo: Cortez; Recife: Massangana, 2001.

ANDRADE, M. C. A terra e o homem no Nordeste. São Paulo: Brasiliense, 1964.

ASSIS, T. R. P. Sociedade civil e a construção de políticas públicas na região semiárida brasileira: o caso do Programa Um Milhão de Cisternas Rurais (P1MC). Revista de Políticas Públicas, São Luís, v. 16, n. 1, jan.-jun. 2012.

ATLAS DO DESENVOLVIMENTO HUMANO NO BRASIL. Disponível em: http://atlasbrasil.org. br/2013/. Acesso em: 10 set. 2017.

BRANDÃO, C. R. Saber da classe e educação popular. In: BRANDÃO, C. R. O ardil da ordem caminhos e armadilhas da educação popular. Campinas: Papirus, 1986.

BRASIL. MDA/SDT. Marco referencial para apoio ao desenvolvimento de territórios rurais. Série documentos institucionais 02-2005. Brasília: SDT, 2005.

CALIXTO, J. S. et al. Trabalho, terra e geração de renda em três décadas de reflorestamentos no alto Jequitinhonha. Rev. Econ. Sociol. Rural, Brasília, v. 47, n. 2, jun. 2009.

CUNHA, E. Os Sertões: campanha de Canudos. 37. ed. Rio de Janeiro: Livraria Francisco Alves, 1995.

DELGADO, N. G.; GRISA, C. Políticas de desenvolvimento territorial e pobreza rural no Brasil. Estudos, Sociedade e Agricultura, Rio de Janeiro, v. 22, n. 1, 2014.

DUQUE, J. G. O Nordeste e as lavouras xerófilas. Fortaleza: Banco do Nordeste do Brasil, 2004.

FACÓ, R. Cangaceiros e fanáticos. 4. ed. Rio de Janeiro: Civilização Brasileira, 1976.

FUNDAÇÃO JOÃO PINHEIRO (FJP). Plano de desenvolvimento do vale do Jequitinhonha. Belo Horizonte: Fundação João Pinheiro, 2018.

FREYRE, G. Nordeste. 3. ed. Rio de Janeiro: José Olympio, 1961.

GALIZONI, F. M. A terra construída. Fortaleza: Etene/BNB, 2007.

. et al. Estratégias familiares de convívio com o Semiárido. In: (org). Lavradores, águas e lavouras. Belo Horizonte: Editora UFMG, 2013.

GOMES, G. M. Novas secas em velhos sertões. Brasília: Ipea, 2001.

GOMES, U. A. F. Água em situação de escassez: água de chuva para quem? Tese (doutorado), UFMG, 2012. 
IBGE. Censo Demográfico, 2010. Disponível em: ftp://ftp.ibge.gov.br/Censos/Censo_Demografico_2010/Resultados_Diario_Oficial_da_Uniao_2010_11_04/MG2010.pdf. Acesso em: 5 mar. 2017.

INCRA. Tabela com módulo fiscal dos municípios. Disponível em: http://www.incra.gov.br/ tabela-modulo-fiscal. Acesso em: 11 jun. 2018.

INSTITUTO NACIONAL DE METEOROLOGIA (INMET). Balanço hídrico. Disponível em: http://www.inmet.gov.br/portal/index.php?r=agrometeorologia/balancoHidricoClimatico. Acesso em: 2 fev. 2017.

MALVEZZI, R. Semiárido - uma visão holística. Brasília: Confea, 2007.

MARTINS, J. S. Os camponeses e a política no Brasil. Petrópolis: Vozes, 1981.

MINISTÉRIO DO DESENVOLVIMENTO AGRÁRIO (MDA). Balanço de gestão: resultados das ações do Programa de Desenvolvimento Sustentável de Territórios Rurais (Pronat) 2003-2010. Brasília: SDT/MDA, 2010.

MINISTÉRIO DA INTEGRAÇÃO NACIONAL (MIN). Nova delimitação do Semiárido brasileiro. Disponível em: http://www.mi.gov.br/c/document_library/get_file?uuid=oaa2bgb5-aa4d-4b55-a6e1-82fafo762763\&groupId=24915. Acesso em: 23 jun. 2016.

OLIVEIRA, F. Elegia para uma re(li)gião. 2. ed. Rio de Janeiro: Paz \& Terra, 1977.

PORTAL DA TRANSPARÊNCIA. Disponível em: http://transparencia.gov.br/ PortalTransparenciaListaAcoes.asp?Exercicio $=2016 \&$ SelecaoUF $=1 \&$ SiglaUF $=$ MG\&CodMun=4067\&ordem=3\&Pagina=1. Acesso em: 27 jun. 2017.

POSEY, D. A. Interpretando e utilizando a "realidade" dos conceitos indígenas: o que é preciso aprender dos nativos? In: DIEGUES, A. C.; MOREIRA, A. C. C. Espaços e recursos naturais de uso comum. São Paulo: Nupaub/USP, 2001.

SILVA, R. M. A. Entre o combate à seca e a convivência com o Semiárido. Revista Econômica do Nordeste, v. 38, 2007.

TRIBUNAL DE CONTAS DO ESTADO DE MINAS GERAIS (TCEMG). Fiscalizando o TCE. Disponível em: http://fiscalizandocomtce.tce.mg.gov.br/Paginas/Gastos. Acesso em: 27 jun. 2017.

VASCONCELOS, M. B. Poços para captação de águas subterrâneas: revisão de conceitos e proposta de nomenclatura. In: XVIII Congresso Brasileiro de Águas Subterrâneas, 2014, Belo Horizonte. Anais [...]. São Paulo: Associação Brasileira de Águas Subterrâneas, 2014. 


\section{Jeter Liano Silva}

Engenheiro ambiental, Mestre, técnico da Prefeitura Municipal de Montes Claros, Minas Gerais

Email: jeterliano@hotmail.com

ORCID: 0000-0002-4146-6291

Contribuição de autoria: conceituação; curadoria de dados; análise formal; investigação/pesquisa; administração do projeto; escrita e primeira redação.

\section{Eduardo Magalhães Ribeiro}

Economista, Doutor, professor titular do Instituto de Ciências Agrárias (ICA)/UFMG.

Email: eduardoribeiromacuni@gmail.com

ORCID: 0000-0002-4330-2346

Contribuição de autoria: conceituação; análise formal; obtenção de financiamento; investigação/pesquisa; metodologia; administração do projeto; recursos; supervisão/orientação; escrita, revisão e edição.

\section{Vico Mendes Pereira Lima}

Engenheiro agrícola, Doutor em Ciência do Solo, professor do IFNMG (Campus Almenara), diretor de Pesquisa, Pós-graduação e Inovação do IFNMG.

Email: vicomendes@hotmail.com

ORCID: 0000-0002-7214-6071

Contribuição de autoria: conceituação; análise formal; investigação/pesquisa; metodologia; escrita, revisão e edição. 


\section{Leo Heller}

Engenheiro civil, Doutor, professor titular aposentado do Departamento de Engenharia Sanitária e Ambiental da UFMG; pesquisador da Fundação Oswaldo Cruz (Fiocruz).

Email: leo.heller@fiocruz.br

ORCID: 0000-0003-0175-0180

Contribuição de autoria: conceituação; análise formal; metodologia; escrita, revisão e edição.

Submissão: 5 de agosto de 2019.

Aprovação: 8 de abril de 2020 .

Como citar: SILVA, J. L.; RIBEIRO, E. M.; LIMA, V. M. P; HELLER, L. As secas no Jequitinhonha: demandas, técnicas e custos do abastecimento no Semiárido de Minas Gerais. Revista brasileira de estudos urbanos e regionais. v. 22, E202013, 2020. DOI 10.22296/23171529.rbeur.202013

Artigo licenciado sob Licença Creative Commons CC BY-NC 4.o.

https://creativecommons.org/licenses/by-nc/4.o/deed.pt_BR 